\title{
Author Correction: 22q13 deletion syndrome: communication disorder or autism? Evidence from a specific clinical and neurophysiological phenotype
}

Laura Ponson ${ }^{1,2}$, Marie Gomot ${ }^{1}$, Romuald Blanc ${ }^{2,3}$, Catherine Barthelemy ${ }^{1}$, Sylvie Roux ${ }^{1}$, Arnold Munnich ${ }^{4,5}$, Serge Romana ${ }^{4,6}$, Nadia Aguillon-Hernandez ${ }^{1}$, Valérie Malan ${ }^{4,6}$ and Frédérique Bonnet-Brilhault ${ }^{1,2}$

Correction to: Translational Psychiatry (2018) 8: 146; https://doi.org/10.1038/s41398-018-0212-9; Published online 8 August 2018

Since the online publication of the above article, the authors have noted errors with the author list. The author names were listed as '(last name)(first name)' instead of '(first name)(last name)'.

The authors and publisher apologise for any inconvenience caused by this error.

The correct author list is:
Laura Ponson, Marie Gomot, Romuald Blanc, Catherine Barthelemy, Sylvie Rouch, Arnold Munnich, Serge Romana, Nadia Aguillon-Hernandez, Valérie Malan and Frédérique Bonnet-Brillhault.

This has now been corrected in both the original PDF and HTML versions of the article.

Published online: 28 February 2019

Correspondence: Laura Ponson (L.PONSON@chu-tours.fr)

'UMR 1253, iBrain, Université de Tours, Inserm, Tours, France

${ }^{2}$ Centre Universitaire de Pédopsychiatrie, CHRU de Tours, Tours, France

${ }^{3}$ Université Paris Descartes, Sorbonne Paris Cité, Institut de Psychologie,

Laboratoire de Psychopathologie et Processus de Santé (EA 4057), Paris, France

${ }^{4}$ Université Paris Descartes, Sorbonne Paris Cité, Paris, France

${ }^{5}$ Laboratory of Molecular and Pathophysiological Bases of Cognitive Disorders, INSERM UMR 1163, Imagine Institute, Necker-Enfants Malades Hospital, Paris, France

${ }^{6}$ Service d'Histologie-Embryologie et Cytogénétique, Hôpital Necker-Enfants Malades, AP-HP, Paris, France

These authors contributed equally: Valérie Malan, Frédérique Bonnet-Brilhault

(c) (i) Open Access This article is licensed under a Creative Commons Attribution 4.0 International License, which permits use, sharing, adaptation, distribution and reproduction (c) in any medium or format, as long as you give appropriate credit to the original author(s) and the source, provide a link to the Creative Commons license, and indicate if changes were made. The images or other third party material in this article are included in the article's Creative Commons license, unless indicated otherwise in a credit line to the material. If material is not included in the article's Creative Commons license and your intended use is not permitted by statutory regulation or exceeds the permitted use, you will need to obtain permission directly from the copyright holder. To view a copy of this license, visit http://creativecommons.org/licenses/by/4.0/. 